\title{
Land cover classification in SE Asia using near and short wave infrared bands
}

\author{
H. P. SATO*† and R. TATEISHI \\ $\dagger$ Geography and Crustal Dynamics Research Center, Geographical Survey \\ Institute, Tsukuba 305-0811, Japan \\ $\$$ Center for Environmental Remote Sensing (CEReS), Chiba University, \\ Chiba 263-8522, Japan
}

(Received 15 October 2002; in final form 11 July 2003)

\begin{abstract}
A land cover classification map is necessary for modelling interactions between the land surface and the atmosphere, monitoring the environment and estimating food production. In order to classify land cover in SE Asia in 2000, Normalized Difference Vegetation Index (NDVI), reflectance of nearinfrared (NIR) band, and reflectance of short wave infrared (SWIR) band of Systeme pour l'Observation de la Terre (SPOT) VEGETATION data were used in this study. First, ground data were collected for training data. In addition, supervised classification was performed on twelve months of NDVI data. As a result, some deserts and peripheral sparse vegetative areas were classified into urban, compared with the world atlas. Secondly, the number of months when the reflectance of the SWIR band is higher than that of the NIR band was counted (SWIR > NIR month-count condition) in each pixel, and pixels with counts of 10 were classified as Sparse Herbaceous/Shrub and of 11 or 12 were classified as Bare Areas, respectively. Finally, land cover was classified based on the SWIR $>$ NIR month-count condition combined with NDVI, and it was compared with the existing land cover map. It was found that the SWIR $>$ NIR month-count condition gives a better result for areas of non- or sparsely vegetative classification than when using only NDVI.
\end{abstract}

\section{Introduction}

In studying and monitoring the global environment, land cover information derived from remote sensing data is necessary (Townshend 1992). For global land cover mapping, the Normalized Difference Vegetation Index (NDVI) calculated from the reflectance of the red and near-infrared (NIR) bands has been used in many previous studies. For example, Defries and Townshend (1994) classified global land cover into 11 items that were selected primarily to conform with Simple Biosphere $(\mathrm{SiB})$ legend, using monthly NDVI data (resolution: $8 \mathrm{~km}$ ) of 1987 from the National Oceanic and Atmospheric Administration (NOAA) Advanced Very High Resolution Radiometer (AVHRR). Supervised classification by the maximum likelihood method was performed on the NDVI data. Recently, unsupervised classification was performed on global NDVI data (resolution: $1 \mathrm{~km}$ ) from AVHRR.

\footnotetext{
*Corresponding author; e-mail: hsato@gsi.go.jp
} 
The result was obtained as the International Geosphere-Biosphere Programme, Data and Information System (IGBP-DIS) data classified into 17 items (Loveland et al. 2000) and distributed in the Global Land Cover Characteristics (GLCC) database of NOAA. To increase classification accuracy, Defries et al. (1995) used not only NDVI but also a combination of NDVI, visible, NIR and thermal bands of AVHRR data, and obtained a 13-item global land cover map.

In comparison with the NOAA AVHRR sensors, the Systeme pour l'Observation de la Terre (SPOT) VEGETATION (VGT) sensor was designed with a number of improvements for studying the vegetation and land surface (Xiao et al. 2002b). SPOT VGT, launched in 1998, has four spectral bands, blue $(430-470 \mathrm{~nm})$, red $(610-680 \mathrm{~nm})$, NIR $(780-890 \mathrm{~nm})$ and SWIR $(1580-1750 \mathrm{~nm})$ at a resolution of approximately $1 \mathrm{~km}\left(1^{\circ}: 112\right.$ pixels). These bands are equivalent to band 1 (450 $520 \mathrm{~nm})$, band $3(630-690 \mathrm{~nm})$, band $4(760-900 \mathrm{~nm})$ and band $5(1550-1750 \mathrm{~nm})$ of the Landsat Thematic Mapper (TM), respectively (table 1). Numerous Landsatbased image analyses have used NIR and short wave infrared (SWIR) bands in land cover classification; however, there are few studies on the use of NIR and SWIR band time series data for land cover mapping. The objective of this study is to explore the potential of multi-temporal NIR and SWIR band SPOT VGT data for land cover mapping in SE Asia in 2000. The number of months when the reflectance of the SWIR band is higher than that of the NIR band was counted (SWIR > NIR month-count condition) in each pixel. This is the first paper assessing the effectiveness of SWIR $>$ NIR month-count condition in land cover mapping.

\section{Method}

\subsection{Remote sensing data}

In this study, 10-day syntheses of SPOT VGT data (VGT-S10 products) of CY2000 were downloaded from the web site of http://free.vito.vgt.be. Downloaded data contain the NDVI and reflectance of these bands in 8-bit and 16-bit digital number (DN) values at a resolution of about $1 \mathrm{~km}$, respectively. In the VGT-S10 products, selection of pixels for synthesis is based on the maximum NDVI value, in order to ensure global land coverage with minimum effect of cloud cover (Xiao et al. 2002a). One month has three VGT-S10 products (day 1-10, day 11-20, and day 21 to the last day of a month). To reduce the possibilities of cloud contamination as well as to ease the problems of handling large volumes of data, the VGT-S10 products were recomposed into monthly images based on the maximum NDVI value in the month.

Table 1. Comparative listing of SPOT VGT, Landsat TM and NOAA AVHRR sensors.

\begin{tabular}{lcc}
\hline VGT $(\mathrm{nm})$ & TM (nm) & AVHRR (nm) \\
\hline B0 (430-470) & TM1 (450-520) & \\
B2 (610-680) & TM3 (630-690) & CH1 (580-680) \\
B3 (780-890) & TM4 (760-900) & \\
MIR (1580-1750) & TM5 (1550-1750) & Spatial resolution: 1 km \\
Spatial resolution: $1 \mathrm{~km}$ & Spatial resolution: 30m & Revisit time: daily \\
Revisit time: daily & Revisit time: 16-days & \\
\hline
\end{tabular}




\subsection{Relationship between NIR, SWIR and water contained in leaves}

In the vegetative area, the reflectance of the NIR band is the highest. The radiance SWIR band is absorbed by water contained in leaves but not in the NIR band (Tucker 1980). When leaves are dry, the reflectance of the SWIR band increases and that of TM band 5 (SWIR) becomes approximately equal to that of TM band 4 (NIR) (Knipling 1970). On the basis of this relationship between the reflectance of SWIR and NIR bands and water contained in leaves, Hunt et al. (1987) proposed the following Leaf Water Content Index (LWCI).

$$
L=\frac{-\log [1-(I-S)]}{-\log \left[1-\left(I_{F T}-S_{F T}\right)\right]}
$$

In equation(1), $L$ represents LWCI, and $I$ and $S$ represent reflectance of TM bands 4 and 5 , respectively. $I_{\mathrm{FT}}$ and $S_{\mathrm{FT}}$ represent reflectance of TM bands 4 and 5 for leaves with full turgor pressure. In the authors' experience, the more water the leaves contain, the closer the index is to 1 . Conversely, the less water the leaves contain, the closer the index is to 0 . In equation (1), it is assumed that $S<I$ and is always satisfied in vegetative areas but $S>I$ is not considered. Reflectance of the SWIR band is higher than that of the NIR band on dry soil (Ishiyama et al. 1996). In this study, $S>I$ was examined using SPOT VGT data; $S$ and $I$ were replaced by reflectance of SWIR and NIR bands of the VGT-S10 product (Anazawa et al. 2002). It was assumed that if SWIR $>$ NIR is satisfied in some parts of the area, the land cover in that area is non- or sparsely vegetative. The number of months when SWIR $>$ NIR is satisfied (SWIR $>$ NIR month-count condition) was counted in each pixel and the spatial distribution of this number in the study area was examined.

\section{Results}

Figure 1 shows the spatial distribution of the SWIR $>$ NIR month-count condition. In the figure, for a pixel not satisfying the condition, the pixel value is indicated as 0 , and when it satisfies the condition throughout all 12 months, the

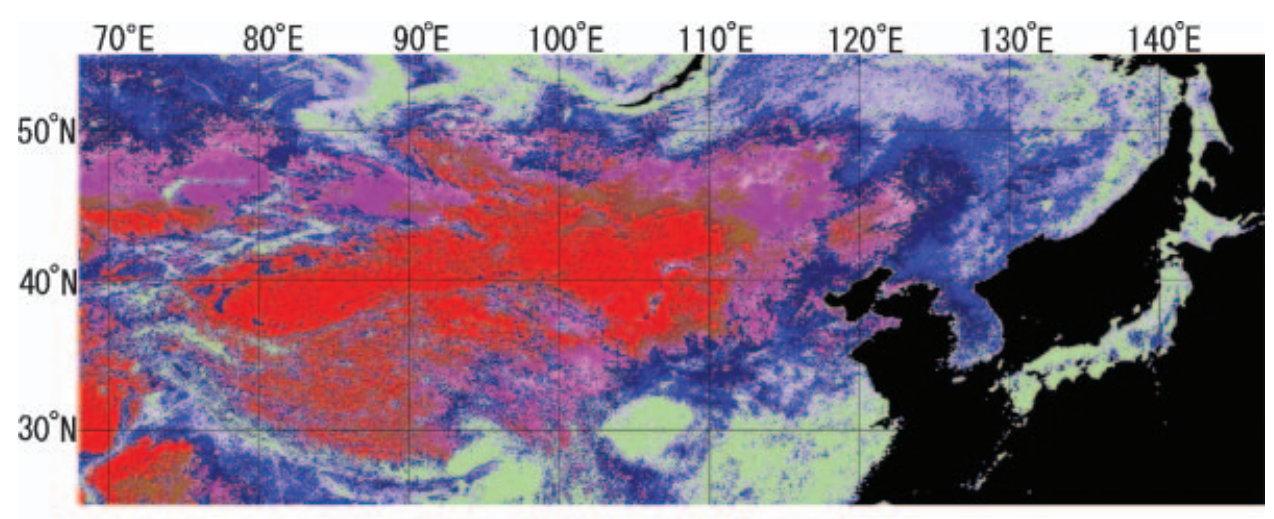

\section{Month counts}

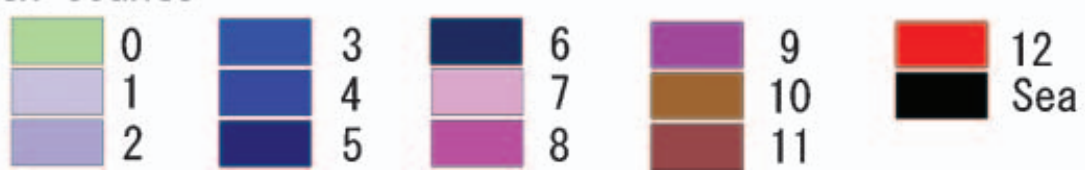

Figure 1. Result of using SWIR $>$ NIR month-count condition. 
value is 12. In the figure, close agreement was obtained between the spatial distribution of the value 12 and the areas of the Great Indian desert $\left(70-75^{\circ} \mathrm{E}\right.$ and $\left.27-30^{\circ} \mathrm{N}\right)$, Takla Makan desert $\left(80-85^{\circ} \mathrm{E}\right.$ and $\left.38-41^{\circ} \mathrm{N}\right)$ and Gobi desert $\left(98-107^{\circ} \mathrm{E}\right.$ and $\left.39-42^{\circ} \mathrm{N}\right)$ shown in the world atlas (Times books 1992). The figure reveals the tendency that as the pixel value decreases, the pixel is found further away from the deserts. Areas whose pixel value is 0 appear, for example, in Assam, India $\left(90-95^{\circ} \mathrm{E}\right.$ and $\left.26-27^{\circ} \mathrm{N}\right)$.

\section{Discussion}

4.1. Relationship between figure 1 and ground data (GD)

Ground data (GD) sites were selected and the relationship between pixel values in figure 1 and GD was examined. In advance, GD sites with the 17 items shown in table 2 were collected. Recently, the Food and Agricultural Organization (FAO) created the Land Cover Classification System (LCCS) for mapping exercises independent of map scale and map use (Di Gregorio and Jansen 2000). Land cover items in table 2 are according to the Sato and Tateishi Land Cover Guideline (STLCG) legend (table 3; Sato and Tateishi 2002), created by the LCCS. Land cover anywhere in the world is identified by combinations of classifiers that are hierarchically arranged in the LCCS. When required, classifiers of environmental attributes (for example, landform, soils and climate) and specific technical attributes (for example, crop type and salinity) can be optionally selected. The LCCS only provides a framework to identify the land cover and, when legend is required, it is necessary to create it using the LCCS. In table 3, the ST-LCG legend satisfies five criteria: (1) applicable to remote sensing data; (2) compatible with the IGBP-DIS legend; (3) provides not only land cover but also crop names; (4) applicable to not

Table 2. Land cover item used in this study.

\begin{tabular}{lccc}
\hline & \multicolumn{2}{c}{ Ground data } & \\
\cline { 2 - 3 } Code and land cover item & $\begin{array}{c}\text { Number of } \\
\text { sites }\end{array}$ & $\begin{array}{c}\text { Pixels counts } \\
\text { in total }\end{array}$ & $\begin{array}{c}\text { IGBP-DIS } \\
\text { code }\end{array}$ \\
\hline 1. Broadleaf Evergreen Forest & 4 & 105 & 2 \\
2. Broadleaf Deciduous Forest & 5 & 228 & 4 \\
3. Needleleaf Evergreen Forest & 6 & 126 & 1 \\
4. Needleleaf Deciduous Forest & 2 & 527 & 3 \\
5. Mixed Forest & 4 & 65 & 5 \\
8. Herbaceous, single layer & 14 & 2906 & 10 \\
9. Herbaceous Vegetation with & 2 & 25 & 10 \\
Sparse Tree/Shrub & 2 & 24 & 16 \\
10. Sparse Herbaceous/Shrub & 6 & 113 & 12 \\
11. Cropland & 2 & 35 & 11 \\
14. Wetland & 2 & 18 & 16 \\
16. Bare Areas & 1 & 22 & 13 \\
17. Urban & 1 & 102 & 12 \\
104. Coconut & 3 & 382 & 10 \\
120. Rice, paddy & 1 & 22 & 11 \\
201. Pasture & 1 & 16 & 11 \\
202. Mixed fields of corn and bean & 1 & & \\
203. Mixed fields of rice and corn & & & 11 \\
\hline
\end{tabular}

Note: This land cover classification is based on the Sato-Tateishi Land Cover Guideline (ST-LCG) legend (Sato and Tateishi 2002) based on the Land Cover Classification System (LCCS) (Di Gregorio and Jansen 2000). 
only global but also national and local land use/land cover; (5) new items could be added easily by using LCCS, unless the hierarchical structure of the ST-LCG legend is disturbed.

In table 3, codes 1-19 of the ST-LCG are at a global level, 31-34, 35, 39 are at national level, and 36-38, 40, 41, 101-166 are at local level. It is difficult to add new items to the conventional legends such as the $\mathrm{SiB}$ and IGBP-DIS legends because of lack of criteria for the addition. In this sense, the fifth criterion is the remarkable characteristics of the ST-LCG legend.

GD sites were gathered for China, Japan, Mongolia and around Lake Baikal in Russia by three methods: field surveys, reference to a world atlas (Times books 1992) and domestic maps, and consultation with people familiar with the on-site

Table 3. Comparative listing of ST-LCG and IGBP-DIS legends.

\begin{tabular}{|c|c|}
\hline ST-LCG code and item & IGBP-DIS code and item \\
\hline 1. Broadleaf Evergreen Forest & 2. Evergreen Broadleaf Forest \\
\hline 101-111 [Crop list] & 2. Evergreen Broadleaf Forest \\
\hline 2. Broadleaf Deciduous Forest & 4. Deciduous Broadleaf Forest \\
\hline 112-117 [Crop list] & 4. Deciduous Broadleaf Forest \\
\hline 3. Needleleaf Evergreen Forest & 1. Evergreen Needleleaf Forest \\
\hline 4. Needleleaf Deciduous Forest & 3. Deciduous Needleleaf Forest \\
\hline 5. Mixed Forest & 5. Mixed Forest \\
\hline 6. Tree Open & 8. Woody savannas and 9. Savannas \\
\hline 31. Broadleaf Evergreen Woodland & 8. Woody savannas and 9. Savannas \\
\hline 32. Broadleaf Deciduous Woodland & 8. Woody savannas and 9. Savannas \\
\hline 33. Needleleaf Evergreen Woodland & 8. Woody savannas and 9. Savannas \\
\hline 34. Needleleaf Deciduous Woodland & 8. Woody savannas and 9. Savannas \\
\hline 7. Shrub & $\begin{array}{l}\text { 6. Closed Shrublands and } \\
\text { 7. Open Shrublands }\end{array}$ \\
\hline 118,119 [Crop list $]$ & $\begin{array}{l}\text { 6. Closed Shrublands and } \\
\text { 7. Open Shrublands }\end{array}$ \\
\hline 8. Herbaceous, single layer & 10. Grasslands \\
\hline 9. Herbaceous with Sparse Tree/Shrub & 10. Grasslands \\
\hline 10. Sparse Herbaceous/Shrub & 16. Barren \\
\hline 11. Cropland & 12. Croplands \\
\hline 120 Rice, paddy & 12. Croplands \\
\hline 121-166 [Crop list] & 12. Croplands \\
\hline 12. Cropland/Natural Vegetation Mosaic & $\begin{array}{l}\text { 14. Cropland/Natural Vegetation } \\
\text { Mosaic }\end{array}$ \\
\hline 13. Tree-Water (Brackish) & 2. Evergreen Broadleaf Forest \\
\hline 14. Wetland & 11. Permanent Wetlands \\
\hline 15. Lichens/Mosses & 10. Grasslands \\
\hline 16. Bare Areas & 16. Barren \\
\hline 35. Consolidated Bare Areas & 16. Barren \\
\hline 36. Bare Rock & 16. Barren \\
\hline 37. Gravels, Stones and Boulders & 16. Barren \\
\hline 38. Hardpan & 16. Barren \\
\hline 39. Unconsolidated Bare Areas & 16. Barren \\
\hline $\begin{array}{l}\text { 40. Bare Soil/Other Unconsolidated } \\
\text { Materials }\end{array}$ & 16. Barren \\
\hline 41. Loose and Shifting Sands & 16. Barren \\
\hline 17. Urban & 13. Urban and Built-up \\
\hline 18. Snow/Ice & 15. Snow and Ice \\
\hline 19. Water & 17. Water Bodies \\
\hline
\end{tabular}

Note: Sato and Tateishi (2002) was revised. 
current situation. The methods were used either separately or together to gather the GD sites. GD sites were plotted on the 60-class unsupervised classification result performed on 12-month VGT-S10 NDVI data. Next, GD sites were manually or automatically delineated. In the automatic delineation, three by three pixel squares of GD sites were automatically generated. As a result, the area of each GD site was at least nine pixels (ca $3 \mathrm{~km}$ by $3 \mathrm{~km}$ ). Each GD site has a monthly NDVI curve for CY2000. When the GD site is classified as Bare Areas or Broadleaf Evergreen Forest, the curve maintains low or high values through the year, respectively. The curve for each GD site was examined, and GD sites that have appropriate NDVI curves for their own classification were finally selected. In table 2 , the number of GD sites and total pixel counts in each item are shown.

In figure 2, average month counts and standard deviation for each item in figure 1 are shown. The land cover classification code on the abscissa in figure 2 corresponds to the code in the left column of table 2. In figure 2, average month counts for code 10 (Sparse Herbaceous/Shrub) and code 16 (Bare Areas) are larger than those of any other codes. Moreover, for both, standard deviations are zero. It is thought to be easy to separate codes 10 and 16 from other codes, but code 10 has the possibility to be confused with code 8 (Herbaceous, single layer). According to FAO's LCCS, land is bisected into primary vegetated and primary non-vegetated classes. When vegetative cover is at least $4 \%$ for at least two months of the year, the land is classified into the former (vegetated), and when vegetative cover is less than $4 \%$ for more than 10 months of the year, the land is classified into the latter (Di Gregorio and Jansen 2000). Here, it is assumed that when the month count is 10, the pixel is classified as Sparse Herbaceous/Shrub, and when it is 11 or 12, the pixel is classified as Bare Areas.

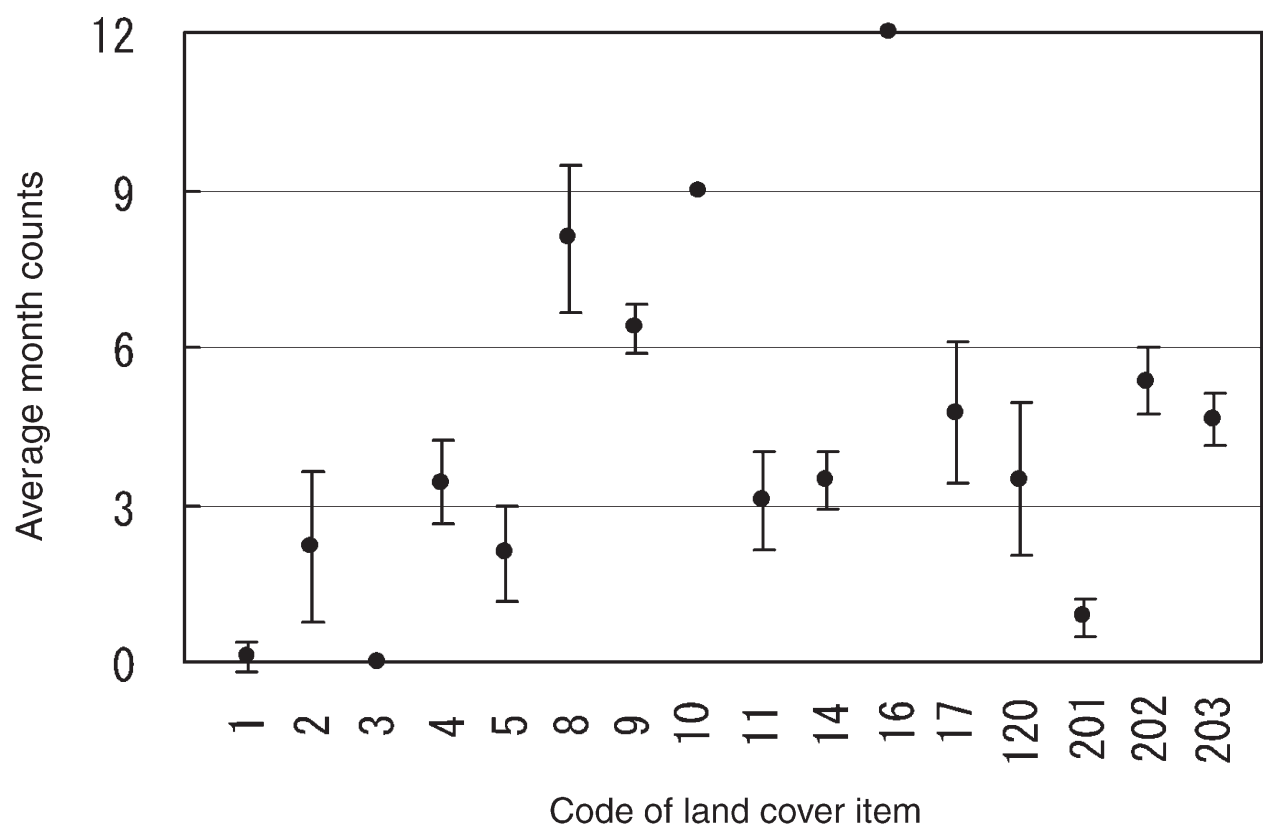

Figure 2. Average month counts in each code of land cover item. The code of land cover item corresponds to the code in the left column of table 2. Codes 10 (Sparse Herbaceous/Shrub), 16 (Bare Areas) and 17 (Urban) are separable, because average month counts for the three codes are different. 
As shown in figure 2, separation between codes 1 and 3 is difficult. Moreover, for example, separation among codes 2, 4, 5, 11 and 14 is also difficult. When codes 1 and 3 are dealt with as one group and codes 2, 4, 5, 11 and 14 are dealt with as another group, the two groups can be easily separated. However, these groups correspond to denser vegetative cover than codes 10 and 16; it seems adequate to use NDVI for land cover mapping, because NDVI is a sensitive index for vegetation. As a result, when the land is non- or sparsely vegetative, the SWIR > NIR month-count condition is used and, when densely vegetative, monthly NDVI is used for land cover classification.

\subsection{Application of SWIR $>$ NIR month-count condition to classification}

Figure 3 shows the result of supervised classification performed on only monthly NDVI. The classification is based on the maximum likelihood method with GD sites. Earth Resources Data Analysis System (ERDAS) software was used as the image processing system. Figure 4 shows the modified classification. First, in the case SWIR > NIR and month count is less than 10, the pixel is classified as the item shown in figure 3. Second, when the count is 10, the pixel is classified as Sparse Herbaceous/Shrub. Finally, when the count is 11 or 12, the pixel is classified as Bare Areas. Figures 5 and 6 are confusion matrices derived from figures 3 and 4 . In figures 5 and 6, accuracies (proportion of the number of pixels on diagonal elements to the number of pixels on GD sites in total) are $98.9 \%$ and $97.0 \%$, respectively. The accuracy in figure 6 is less than that in figure 5. This is because the accuracies of code 8 (Herbaceous, single layer) decreases from 99.5\% to $96.3 \%$ (figures 5 and 6). For code 8 (Herbaceous, single layer) of figure 6, the number of pixels erroneously classified as code 10 (Sparse Herbaceous/Shrub) and code 16 (Bare Areas) became 56 and 38, respectively, thereby, causing decrease of the former. However, when figures 3 and 4 are compared with the world atlas (Times books 1992), areas of the Great Indian desert $\left(70-75^{\circ} \mathrm{E}\right.$ and $\left.27-30^{\circ} \mathrm{N}\right)$, Takla Makan desert (80-85 $\mathrm{E}$ and

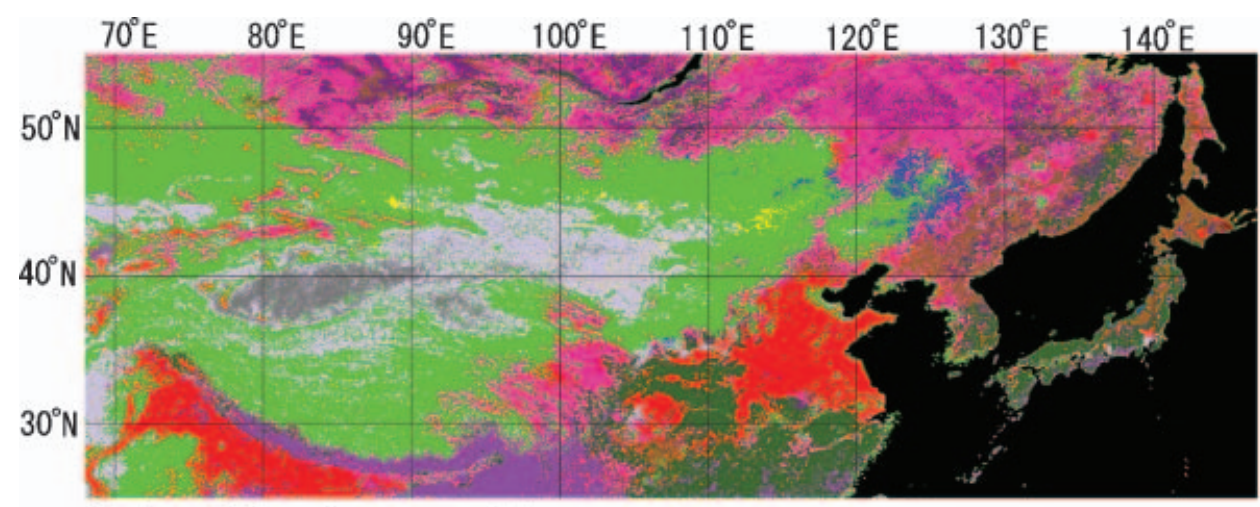

Code of land cover item
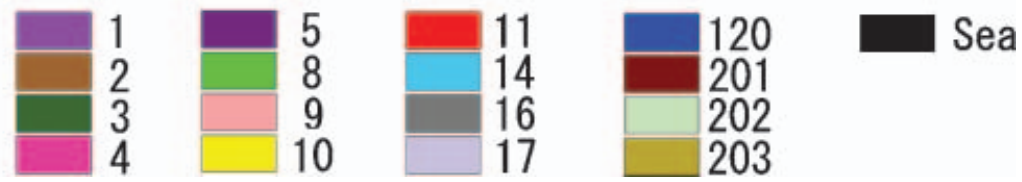

Figure 3. Result of land cover classification using NDVI. The code of land cover item corresponds to the code in the left column of table 2. 


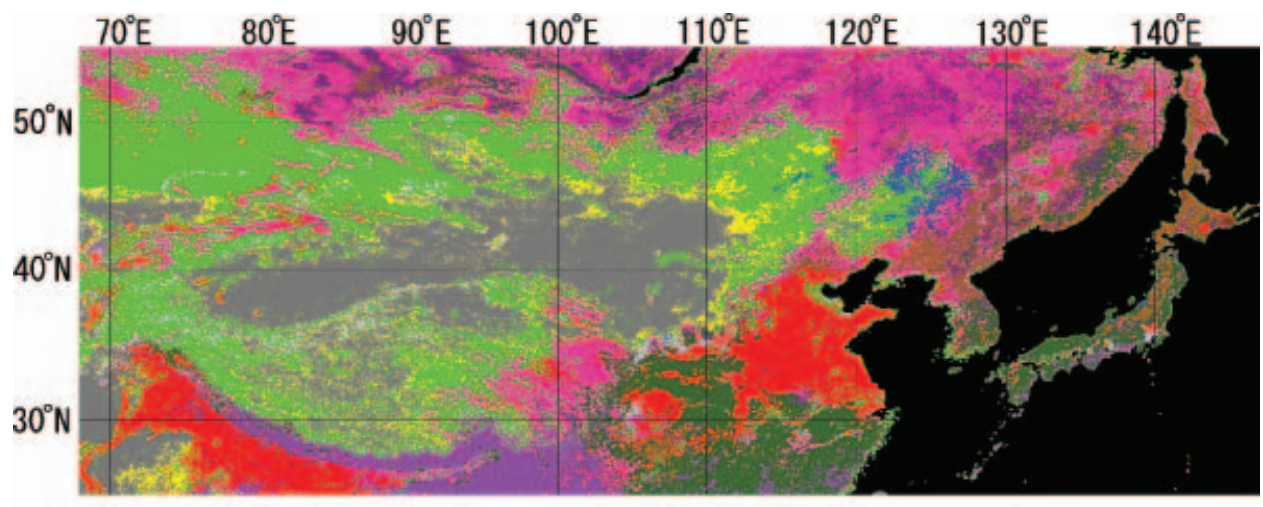

Code of land cover item
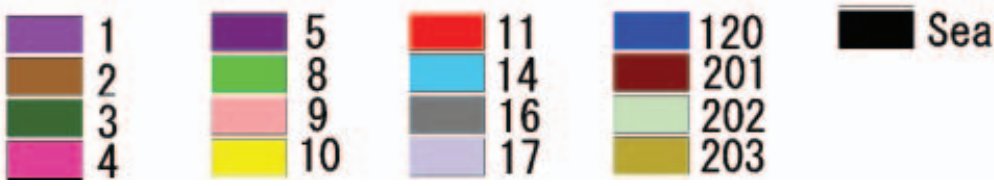

Figure 4. Result of land cover classification using a combination of SWIR $>$ NIR monthcount condition and NDVI. The code of land cover item corresponds to the code in the left column of table 2 .

$\left.38-41^{\circ} \mathrm{N}\right)$, Gobi desert $\left(98-107^{\circ} \mathrm{E}\right.$ and $\left.39-42^{\circ} \mathrm{N}\right)$ and peripheral areas were erroneously classified as Urban in figure 3 and correctly classified as Bare Areas and Sparse Herbaceous/Shrub in figure 4. This result suggests that if the land is non- or sparsely vegetative, the SWIR $>$ NIR month-count condition results in a better classification result than NDVI.

\subsection{Validation of the classification}

According to the world atlas (Times books 1992), border areas between China and Mongolia have large non- and sparsely vegetative areas. The land cover layer

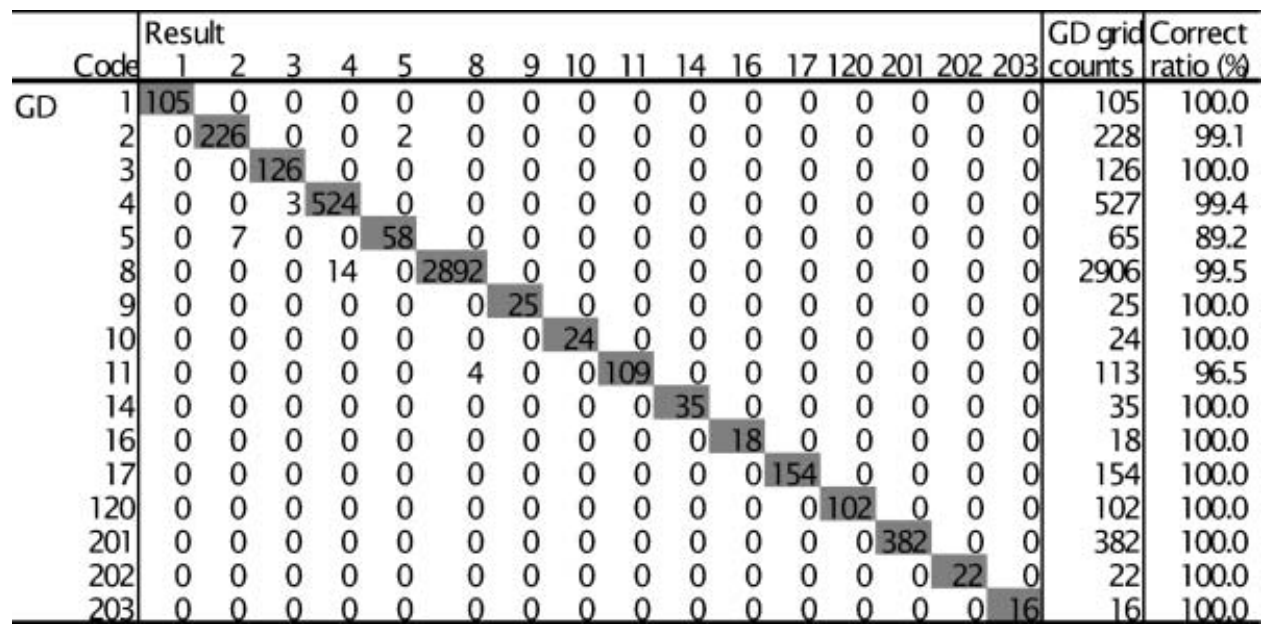

Figure 5. Confusion matrix of land cover classification by NDVI. The code of land cover item corresponds to the code in the left column of table 2. 


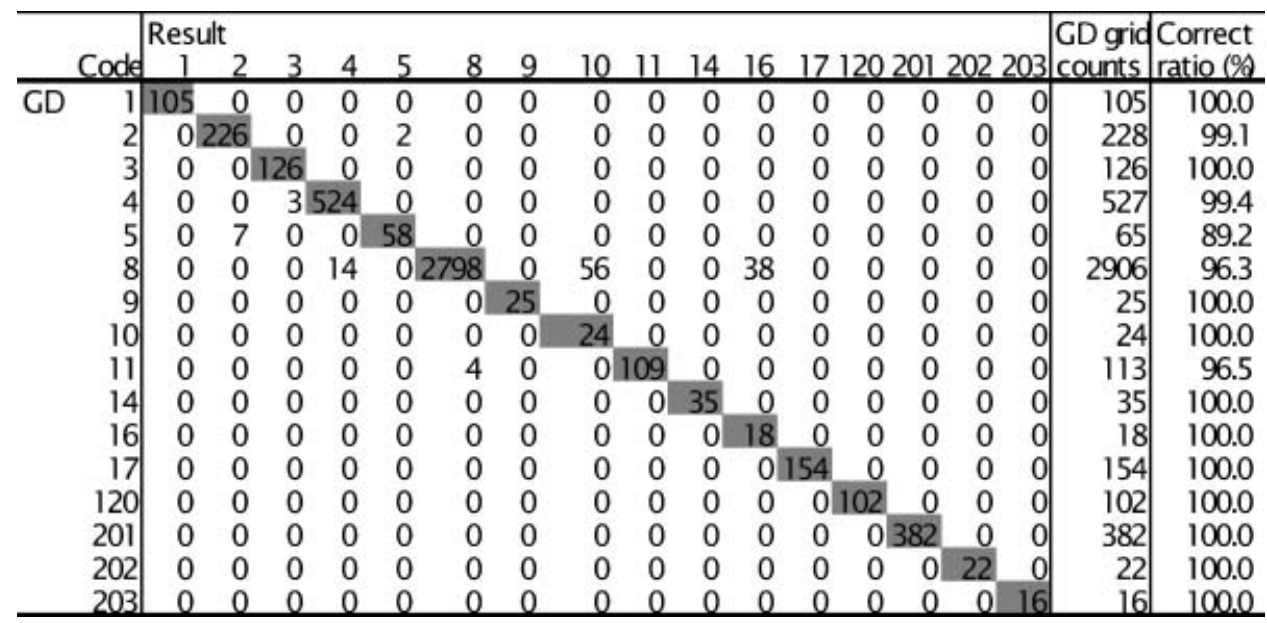

Figure 6. Confusion matrix of land cover classification by a combination of SWIR $>$ NIR month-count condition and NDVI. The code of land cover item corresponds to the code in the left column of table 2.

of the Global Map (GM) of Mongolia that covers the border area (96-102 ${ }^{\circ} \mathrm{E}$ and $40-45^{\circ} \mathrm{N}$ ) was selected as the standard and figures 3 and 4 were compared with the GM. The Global Mapping project is an international collaborative initiative through voluntary participation of national mapping organizations of the world, which aims to develop globally homogeneous geographical datasets at a ground resolution of $1 \mathrm{~km}$. The primary objective of the Global Mapping project is to contribute to sustainable development through the provision of a base framework geographical dataset. Currently, 127 countries, accounting for $80 \%$ of the land area of the Earth, are participating in the project and data from twelve countries have been completed (Masaharu and Akiyama 2003).

In the selected area, there are no GD sites. Resolutions of the GM and VGT$\mathrm{S} 10$ product are $1^{\circ}: 120$ pixels and $1^{\circ}: 112$ pixels, respectively. GM resolution was adjusted to VGT-S10 resolution by re-sampling using the nearest-neighbour method. The land cover layer of the GM is based on IGBP-DIS land cover data in the GLCC database, and the GM data are freely downloaded from the website (http://www.iscgm.org) of the International Steering Committee for GM (Une et al. 2002). In tables 2 and 3, both Bare Areas and Sparse Herbaceous/Shrub on the STLCG legend are equivalent to Barren on the IGBP-DIS legend (Sato and Tateishi 2002). If the pixels of Barren on the GM correspond with the pixels of Bare Areas or Sparse Herbaceous/Shrub in figures 3 and 4, the figures are judged to show correct classification. On the other hand, if these correspond with the pixels of Urban or other items in figures 3 and 4, the figures are judged to show erroneous classification. Table 4 indicates accuracy and error ratio of figures 3 and 4 . According to table 4 , accuracy is $7.78 \%$ and $97.60 \%$ in figures 3 and 4 , respectively, and error ratio is $92.22 \%$ and $2.40 \%$ in figures 3 and 4 , respectively. It became clear that pixels erroneously classified as Urban in figure 3 were correctly classified as Bare Areas and Sparse Herbaceous/Shrub in figure 4.

As a trial, the average value and standard deviation of the SWIR $>$ NIR month counts on the Barren area of the GM of Mongolia (233 350 pixels) were calculated. The average value was 11.6 and standard deviation was 0.76 . This result agrees well 
Table 4. Comparative listing of classification results in figures 3 and 4 on Barren in Global Map of Mongolia (pixel counts: 233 350).

\begin{tabular}{llrc}
\hline Classification result & \multicolumn{1}{c}{ Classified as } & Pixel counts & Ratio (\%) \\
\hline Figure 3 & Sparse herbaceous/Shrub & 2123 & $7.78^{*}$ \\
& Bare areas & 16033 & \\
& Urban & 187041 & $92.22 \dagger$ \\
& Other items & 28153 & \\
Fotal & 233350 & \\
& Sparse herbaceous/Shrub & 11963 & $97.60^{*}$ \\
& Bare areas 4 & 215796 & $2.40 \dagger$ \\
& Urban & 4169 & \\
& Other items & 1422 & \\
\hline
\end{tabular}

Note that Barren in GM Mongolia is equivalent to Sparse Herbaceous/Shrub or Bare Areas in figures 3 and 4.

*Accuracy; †Error ratio.

with the counts for code 10 (Sparse Herbaceous/Shrub) and code 16 (Bare Areas) in figure 2. Next, monthly change of average NDVI in the Barren area of the GM of Mongolia (233 350 pixels) was calculated, as shown in figure 7 (the graph of Barren). In the figure, the monthly changes of average NDVI on the three GD codes 10 (Sparse Herbaceous/Shrub), 16 (Bare Areas) and 17 (Urban) are also shown. As mentioned above, almost all Barren pixels were erroneously classified as code 17 (Urban) by NDVI alone (figures 3 and 5). On comparing the graph of Barren with the other three graphs in figure 7 , this error seems to be caused by the fact that the standard deviation of code 17 of Urban (ca 11) is more than that of code 16 of Bare Areas (ca 2), even if the shape of the Barren graph is similar to that of
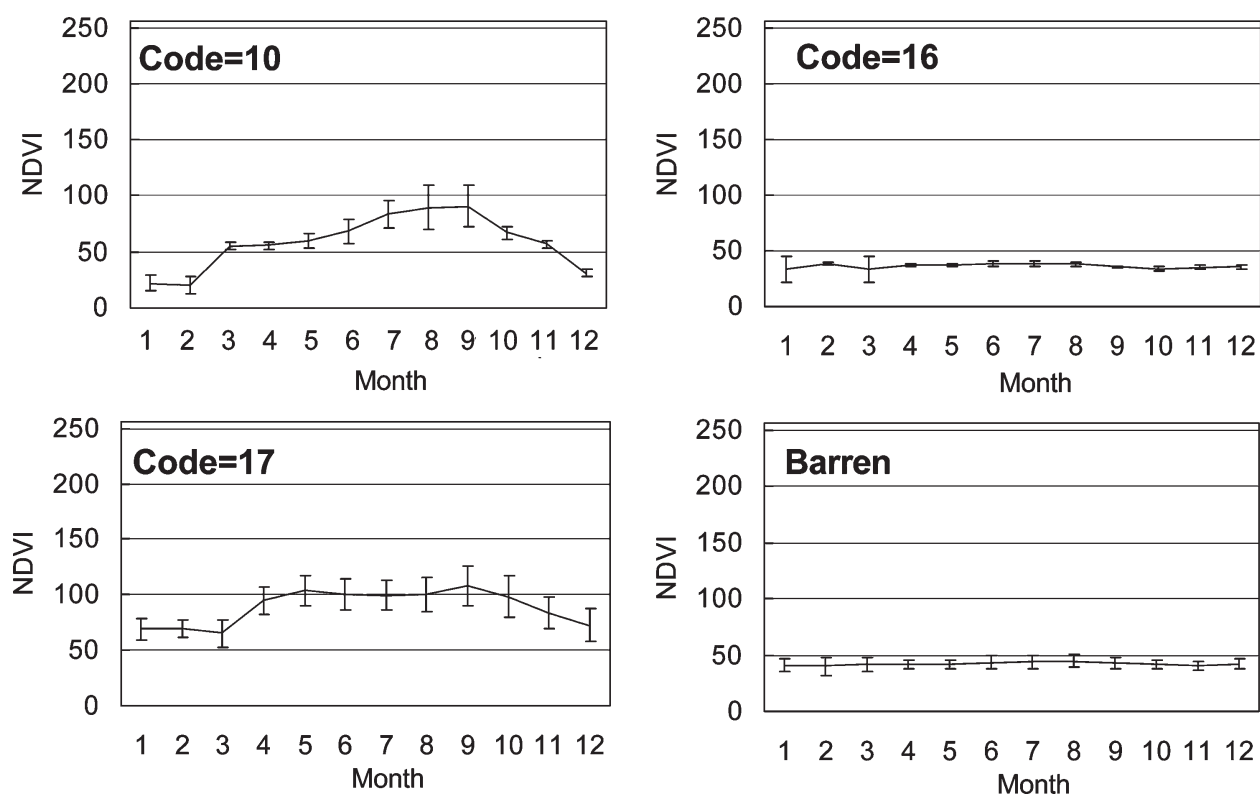

Figure 7. Monthly NDVI changes for the three GD codes and Barren of the Global Map of Mongolia. Monthly average NDVI with standard deviation is shown in the figure. Code 10 is Sparse Herbaceous/Shrub; Code 16 is Bare Areas; Code 17 is Urban. 
code 16 (Bare Areas). Based on the above discussion, it was concluded that the SWIR > NIR month-count condition gives a better result for non- and sparsely vegetative classifications than does NDVI alone.

\section{Conclusion and future study}

This study shows the example of non- and sparsely vegetative area classifications using SWIR and NIR bands, which have been used in few studies. In the future, more effective use of NDVI, SWIR and NIR bands for land cover classification should be studied further. Moreover, monthly SWIR and NIR changes may be used for classification. These bands are robust against water vapour and haze. Studies of land cover classification using these bands will be performed.

\section{Acknowledgments}

The authors express their gratitude to Dr Lin Zhu, Dr Renchin Tsolmon, Mr Mitsuhiko Ebata, Mr Yasunobu Shimazaki, Mr Yosuke Orishimo and other graduate students of Chiba University for ground data collection, and to Mr Izumi Kamiya (Geographical Survey Institute) for helpful advice.

\section{References}

Anazawa, M., Saito, G., Sawada, Y., and Sawada, H., 2002, Utilization of leaf water content index for selected terrestrial ecosystem monitoring using SPOT. Asian Journal of Geoinformatics, 3, 55-62.

Defries, R. S., and Townshend, J. R. G., 1994, NDVI-derived land cover classifications at a global scale. International Journal of Remote Sensing, 15, 3567-3586.

Defries, R., HANSEn, M., and Townshend, J., 1995, Global discrimination of land cover types from metrics derived from AVHRR Pathfinder Data. Remote Sensing of Environment, 54, 209-222.

Di Gregorio, A., and Jansen, L. J. M., 2000, Land Cover Classification System (LCCS) Classification Concepts and User Manual (Rome: Food and Agricultural Organization).

Hunt, E. R., Rock, B. N., and Nobel, P. S., 1987, Measurement of leaf relative water content by infrared reflectance. Remote Sensing of Environment, 22, 429-435.

Ishiyama, T., Nakajima, Y., and Kajiwara, K., 1996, Vegetation index algorithm for vegetation monitoring in arid and semi arid land. Journal of Arid Land Studies, 6, $35-47$.

KNIPLING, E. B., 1970, Physical and physiological basis for the reflectance of visible and near-infrared radiation. Remote Sensing of Environment, 1, 155-159.

Loveland, T. R., Reed, B. C., Brown, J. F., Ohlen, D. O., Zhu, Z., Yang, L., and MERChANT, J. W., 2000, Development of a global land cover characteristics database and IGBP DISCover from 1-km AVHRR data. International Journal of Remote Sensing, 21, 1303-1330.

Masaharu, H., and AkiYama, M., 2003, Publicity activities of Global Mapping at Johannesburg Summit and outcomes of the Summit. Bulletin of the Geographical Survey Institute, 49, 59-69.

SAto, H. P., and TAteishi, R., 2002, Proposal for global land cover guideline legend based on FAO's LCCS. Asian Journal of Geoinformatics, 3, 35-45.

Times Books, 1992, Atlas of the World, 9th edn (London: Times books).

Townshend, J. R. G., 1992, Land cover. International Journal of Remote Sensing, 13, 1319-1328.

TUCKeR, C. J., 1980, Remote sensing of leaf water content in the near infrared. Remote Sensing of Environment, 10, 23-32.

Une, H., KaJikAwa, S., and SAto, H. P., 2002, Application of Global Map for land use/ land cover change study. In Land Use/Cover Changes in Comparative Perspective, edited by Y. Himiyama, M. Hwang and T. Ichinose (Enfield, NH: Science Publishers), pp. 3-19. 
Xiao, X., Moore III, B., Qin, X., Shen, Z., and Boles, S., 2002a, Large-scale observations of alpine snow and ice cover in Asia: using multi-temporal VEGETATION sensor data. International Journal of Remote Sensing, 23, 2213-2228.

Xiao, X., Boles, S., Frolking, S., Salas, W., Moore III, C. B., Li, C., He, L., and Zhao, R., 2002b, Landscape-scale characterization of cropland in China using Vegetation and Landsat TM images. International Journal of Remote Sensing, 23, 3579-3594. 